\title{
Speed Effects on Inherent Rotating Frequency of Motorized Spindle System

\author{
Bo Wang ${ }^{1, a}$, Wei Sun ${ }^{1}$, Kunpeng $\mathrm{Xu}^{2}$, Bangchuan Wen ${ }^{1}$
}

1.School of Mechanical Engineering, Northeastern University, Shenyang 110819, China

2.SANY Group Co.,Ltd, . Shenyang 110027, China

a.wangboblue1113@163.com

Keywords: high speed; spindle system; dynamic characteristic; effect analysis

\begin{abstract}
The paper determines the impact factors of high-speed spindle system including the centrifugal force, gyroscopic moments and the bearing stiffness softening, etc, then builds the general spindle-bearing FEM considering high speeds. Taking a motorized spindle as example, the effect of centrifugal force, gyroscopic effect, the radial stiffness and the coupling factors are analyzed qualitatively and quantitatively. Finally the research shows the variations of bearing radial stiffness, centrifugal force and gyroscopic moments have a significant effect on dynamics of spindle system in high speeds, while modeling the high speed spindle system, above factors must be considered.
\end{abstract}

\section{Introduction}

High-speed cutting is the method of processing parts using cutting speed and feed rate much higher than the conventional process (typically 5-10 times higher than conventional processing). For some extreme cases, spindle speed can arrive $180000 \mathrm{rpm}$, feed speed $80 \mathrm{~m} / \mathrm{min}$ or more ${ }^{[1]}$. High-speed spindle system is one of the most critical technology ensuring the quality of high-speed cutting, whose dynamics directly affect the quality of high-speed cutting process, stability and efficiency. Therefore, the study and optimization of high-speed spindle system dynamics is significant.As the spindle speed continues to rise, researchers ${ }^{[2-4]}$ found that the dynamics of high-speed spindle system is significantly different from its dynamics in stationary state.

This paper identifies the influencing factors of spindle system dynamics induced by high-speed, including centrifugal force, gyroscopic moment and bearing stiffness softening and so on. On this basis, the spindle speed - bearing finite element model considering rotating speed is established based on the FEM. Taking a motorized spindle as example, the impacts of the centrifugal force, gyroscopic moment, bearing radial stiffness and coupling effect of these factors on high-speed spindle system dynamics are investigated.

\section{Influencing factors of spindle system dynamics induced by high-speed}

High-speed cutting commonly uses motorized spindle system. Fig.1 is the structural diagram of spindle system, including the spindle, front and rear bearing group, rotor, stator, shaft rod, shell and all parts of the sleeve and counter balance, etc. The influencing factors of high-speed spindle system dynamics can be divided into three categories: one includes the spindle, tool holder, tool structure size, bearing ${ }^{[5]}$ and static parameters such as the cutting force on tip points ${ }^{[6-7]}$ which does not change with the rotating speed; one is the junctional parameters of the spindle system ${ }^{[8-9]}$, including the surface features of spindle-holder, holder-tool; one is the dynamic mechanical parameters induced by the rotating speed, including the shafting centrifugal force, gyroscopic moment, bearing stiffness and other factors, which is the focus of this paper.

Shafting centrifugal force. Centrifugal force is the generated force while breaking away from the rotating center, the centrifugal force of spindle system during rotating includes the shafting centrifugal force generated by the system itself and the centrifugal force with the ball rotating in 
ball bearing ${ }^{[3,10]}$. As the shaft diameter of spindle shafting is small and a very good dynamic balance has been done before leaving the factory, many scholars ${ }^{[11-12]}$ commonly neglected the impacts of centrifugal force on the spindle dynamics during the dynamic analysis. In fact, the shaft centrifugal force is an objective existence in the high speed mode ${ }^{[13]}$. The centrifugal force in this paper mainly refers to the shafting centrifugal force, while the centrifugal force generated by ball bearing stiffness attributed to the influencing factors of bearing stiffness.

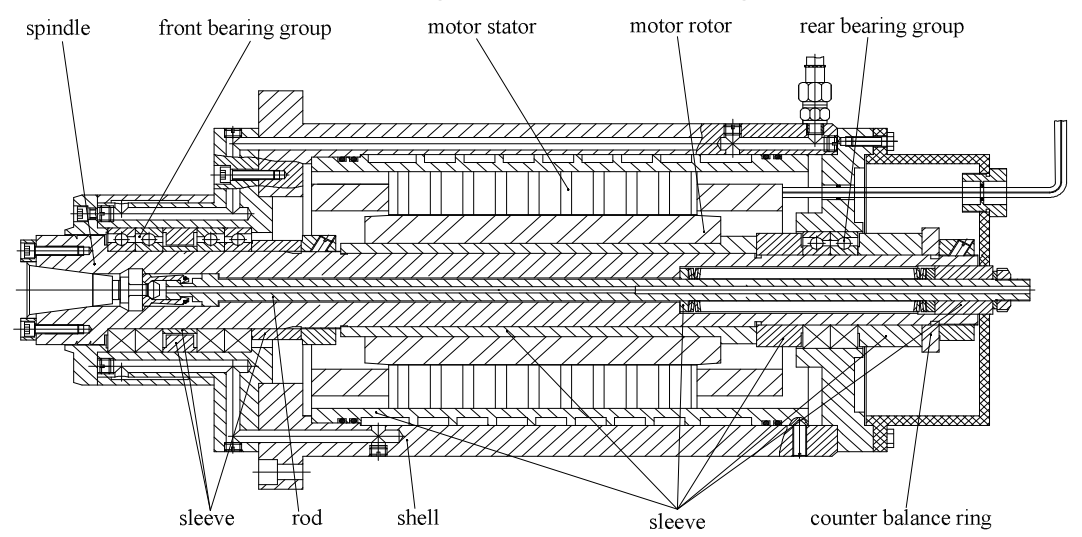

Fig. 1. Motorized spindle system structure

Gyroscopic moment. Gyroscopic effect is the inertia of rotating object maintaining its rotating direction (rotating axis), which is the performance of rotating objects inertia. In the dynamics analysis of high-speed spindle system, most researchers consider the impact of gyroscopic moment on the high speed spindle system dynamics $^{[14]}$.

Bearing stiffness. Taking motorized spindle as representation, the high-speed spindle system mostly select ball bearings. In the dynamic analysis, all researcher take the contributions of bearings stiffness for system dynamics into account ${ }^{[10-11]}$. However, the impact of high-speed on the induced variation in bearing stiffness, thereby affecting the dynamics of spindle system, is less studied. This paper is just for this content.

High speed has a significant impact on the ball bearing stiffness, taking the motorized shaft system in the paper as an example. Front bearing group model SNR7010H, after bearing group model SNR7009H. When the bearing contact angle is $25^{\circ}$, axial and radial pre-load is $14500 \mathrm{~N}$, the stiffness of front and rear radial bearings group in system changing with the speed are calculated and the curves are also painted, as shown in Fig.2. Therefore, the bearing stiffness becomes smaller in high speed mode, appearing bearing softening, and the softening will strongly affect the spindle system

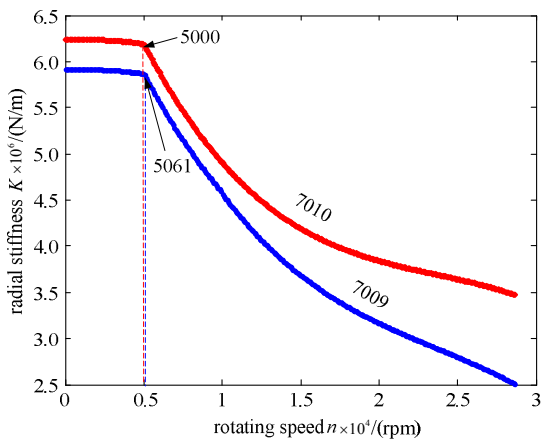

Fig. 2. Ball bearing radial stiffness softening curve dynamics.

\section{Finite element modeling of high-speed spindle system dynamics}

Modeling principles with the impact of rotating speed on high speed spindle system. The spindle system is simulated by Timoshenko beam element which considers the shear role. The kinetic energy of beam elements, strain energy and external power are individually solved. Using the Hamilton's principle combined with the bearing stiffness matrix obtaining the Lagrange operator of spindle system, and deducing the finite element motion equations with the impact of spindle speed in consideration. 


$$
\left\{\begin{array}{l}
\rho A \frac{\mathrm{d}^{2} v}{\mathrm{~d} t^{2}}-\frac{\partial}{\partial x}\left[k_{s} A G\left(\frac{\partial v}{\partial x}-\theta_{z}\right)-\frac{1}{2} E A\left(\frac{\partial v}{\partial x}\right)^{3}\right]-q_{y}-\Omega^{2} \rho A v=0 \\
\rho A \frac{\mathrm{d}^{2} w}{\mathrm{~d} t^{2}}-\frac{\partial}{\partial x}\left[k_{s} A G\left(\frac{\partial w}{\partial x}-\theta_{y}\right)-\frac{1}{2} E A\left(\frac{\partial w}{\partial x}\right)^{3}\right]-q_{z}-\Omega^{2} \rho A w=0 \\
\rho I \frac{\mathrm{d}^{2} \theta_{y}}{\mathrm{~d} t^{2}}+\Omega \rho J \frac{\mathrm{d} \theta_{z}}{\mathrm{~d} t}-E I \frac{\partial^{2} \theta_{y}}{\partial x^{2}}+k_{s} A G\left(\frac{\partial w}{\partial x}-\theta_{y}\right)-m_{y}=0 \\
\rho I \frac{\mathrm{d}^{2} \theta_{z}}{\mathrm{~d} t^{2}}-\Omega \rho J \frac{\mathrm{d} \theta_{y}}{\mathrm{~d} t}-E I \frac{\partial^{2} \theta_{z}}{\partial x^{2}}-k_{s} A G\left(\frac{\partial v}{\partial x}-\theta_{z}\right)-m_{z}=0
\end{array}\right.
$$

In the bearing location of spindle system, the bearing is simulated as the spring bearing model, angular contact ball bearings bears the radial and bearing joint load, and angular contact ball bearings installed in pairs can also withstand torque loads. Therefore, while analyzing the stiffness of bearing supporting location, the radial and angular stiffness should be considered simultaneously. Each element of stiffness matrix can be expressed as equ.(2). $\mathrm{X}$ axis represents the axial direction of spindle system; $\mathrm{y}$ and $\mathrm{z}$ is respectively equidirectional and vertical to the applied radial static load.

$$
\boldsymbol{K}_{N r}=\left|\begin{array}{ll}
\frac{\partial F_{y}}{\partial v} & \frac{\partial F_{y}}{\partial w} \\
\frac{\partial F_{z}}{\partial v} & \frac{\partial F_{z}}{\partial w}
\end{array}\right| \quad \boldsymbol{K}_{N \mathrm{a}}=\left|\begin{array}{ll}
\frac{\partial M_{y}}{\partial \theta_{y}} & \frac{\partial M_{z}}{\partial \theta_{z}} \\
\frac{\partial M_{y}}{\partial \theta_{y}} & \frac{\partial M_{z}}{\partial \theta_{z}}
\end{array}\right|
$$

Through collecting the motion equation of each shaft section as group and introducing the bearing stiffness matrix, the motion equation of spindle considering rotating speed can be obtained, rearranged as

$$
\boldsymbol{M}\{\ddot{x}\}+\boldsymbol{C}\{\dot{x}\}+\boldsymbol{K}\{x\}=\boldsymbol{F}(t)
$$

$\boldsymbol{M}$ the spindle mass matrix, $\boldsymbol{M}=\boldsymbol{M}_{T}^{b}+\boldsymbol{M}_{R}^{b}, \boldsymbol{M}_{T}^{b}$ spindle translational mass matrix, $\boldsymbol{M}_{R}^{b}$ spindle rotating mass matrix; $\boldsymbol{C}=\Omega \boldsymbol{G}^{b}+\boldsymbol{C}^{s}, \Omega \boldsymbol{G}^{b}$ axis gyroscopic force matrix, $\boldsymbol{C}^{s}$ structural damping matrix; $\boldsymbol{K}=\boldsymbol{K}^{b}+\boldsymbol{K}^{B}-\Omega^{2} \boldsymbol{M}_{C}^{b}, \boldsymbol{K}^{b}$ spindle stiffness matrix, $\boldsymbol{K}^{B}$ bearing stiffness matrix, $\Omega^{2} \boldsymbol{M}_{T}^{b}$ the spindle stiffness matrix generated by centrifugal force; $\boldsymbol{F}(t)$ force vector, including the distribution and concentration force operating in spindle.

\section{Influencing factors analysis of spindle system dynamics in high speed mode}

Structural parameters and finite element model of a spindle system. Fig.1 shows the simplified structure of the motorized spindle system, the shaft sectional dimensions are shown in Table 1. As the spindle ignores the rod, so the model established in this paper is hollow. Bearing position and the radial stiffness in the stationary state are shown in Table 2.

The finite element model of spindle system is shown in Fig.3. As using Timoshenko beam element modelling the spindle, each node has six degrees of freedom, including three translational and three rotational degrees of freedom. Motor rotor rotates with the spindle. Spindle front bearing set includes two pairs of four bearings, installed in the form of series and hybrid installation of face to face; rear bearing set includes a pair of two bearings, installed in the form of face to face. Modeling process omits the spindle jacket, sleeves, and the broaches organization in spindle. 
Table 1 Simplified size of motorized spindle system / mm

\begin{tabular}{cccc|cccc|cccc}
\hline No. & Length & $\begin{array}{c}\text { Outer } \\
\text { diameter }\end{array}$ & $\begin{array}{c}\text { Inner } \\
\text { diameter }\end{array}$ & No. & Length & $\begin{array}{c}\text { Outer } \\
\text { diameter }\end{array}$ & $\begin{array}{c}\text { Inner } \\
\text { diameter }\end{array}$ & No. & Length & $\begin{array}{c}\text { Outer } \\
\text { diameter }\end{array}$ & $\begin{array}{c}\text { Inner } \\
\text { diameter }\end{array}$ \\
\hline 1 & 10 & 70 & 31 & 11 & 19 & 50 & 16 & 21 & 20 & 96 & 16 \\
2 & 10 & 70 & 28 & 12 & 18 & 49 & 16 & 22 & 20 & 96 & 16 \\
3 & 13 & 70 & 25 & 13 & 19 & 49 & 16 & 23 & 24 & 96 & 30 \\
4 & 7 & 70 & 21 & 14 & 24 & 96 & 16 & 24 & 21 & 47 & 30 \\
5 & 10 & 50 & 21 & 15 & 20 & 96 & 16 & 25 & 22 & 45 & 30 \\
6 & 16 & 50 & 27 & 16 & 20 & 96 & 16 & 26 & 23 & 45 & 30 \\
7 & 18 & 50 & 21 & 17 & 20 & 96 & 16 & 27 & 16 & 45 & 30 \\
8 & 18 & 50 & 21 & 18 & 20 & 96 & 16 & 28 & 18 & 45 & 30 \\
9 & 16 & 50 & 16 & 19 & 20 & 96 & 16 & 29 & 20 & 45 & 30 \\
10 & 18 & 50 & 16 & 20 & 20 & 96 & 16 & 30 & 20 & 45 & 30 \\
& & & & & & & & 31 & 20 & 45 & 30 \\
\hline
\end{tabular}

Table 2 Bearing distributing location table of motorized spindle system

\begin{tabular}{ccccccc}
\hline Bearing number & 1 & 2 & 3 & 4 & 5 & 6 \\
\hline Node location & 6 & 7 & 9 & 10 & 27 & 28 \\
$\begin{array}{c}\text { Distance from the front surface } / \mathrm{mm} \\
\text { Radial stiffness/N/m }\end{array}$ & 50 & 66 & 102 & 118 & 466 & 482 \\
\hline & & & $6.236 \mathrm{e}+8$ & & $5.916 \mathrm{e}+8$ \\
\hline
\end{tabular}

Fig. 3. Finite element model of the spindle system

\section{Variation of spindle dynamics induced by rotating speed}

(1) the impact of centrifugal force

Figure 4 is the curves in which the first four natural frequencies of the spindle system change with the rotating speed. As can be seen from the Figure, when the speed of spindle system is low(under 500 $\mathrm{rad} / \mathrm{s}$ ), the natural frequency can be approximated with that in the stationary state; when the spindle speed is $3000 \mathrm{rad} / \mathrm{s}$, the first four natural frequencies are respectively $80.83 \%, 97.6 \%, 98.38 \%$ and $98.6 \%$ of that in the stationary state.

(2) the impact of gyroscopic effects

Taking the impact of gyroscopic moment into consideration, and through calculating the natural frequencies with different rotating speeds (only consider the bending of axis), 1-4 order natural frequency curve are drawn. Calculating the critical speed of motorized spindle system by Campbell diagram, as shown in Figure 5. It can be seen from the figure that the impact of system gyroscopic moment on 1-order natural frequency is little, while the impacts on the high natural frequency are greater. 


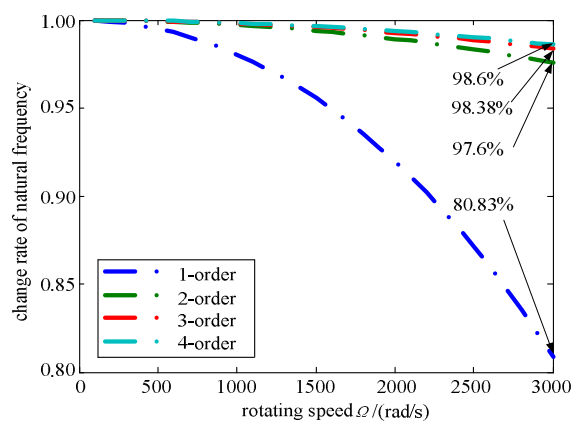

Fig. 4. Natural frequencies vs centrifugal force

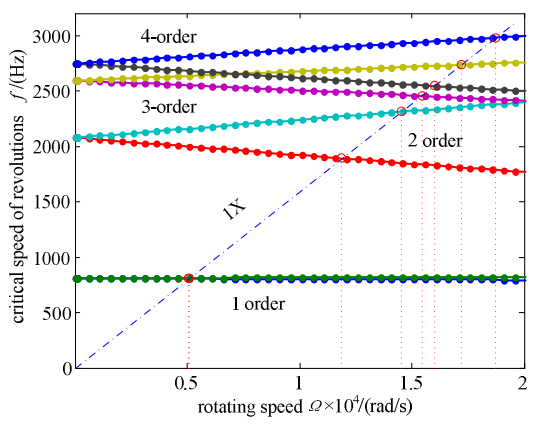

Fig. 5. Campbell diagram

The impact of various coupling factors. Coupling the centrifugal force, gyroscopic moment, and bearing stiffness, the impact law of these three factors on the dynamics of motorized spindle system is analyzed. Fig. 6 is the variation curve of natural frequencies with the rotating speed changing from 0 to $3000 \mathrm{rad} / \mathrm{s}$. The natural frequencies in stationary state and those under the individual and coupling influence of centrifugal force, gyroscopic moment, bearing stiffness when rotating speed is 3000 rad/s (ie 28647.89rpm) are listed in Table 7.

From Fig.6, When $\Omega<500 \mathrm{rad} / \mathrm{s}$ the natural frequencies change slowly, as the speed increases, the natural frequency change intensively.

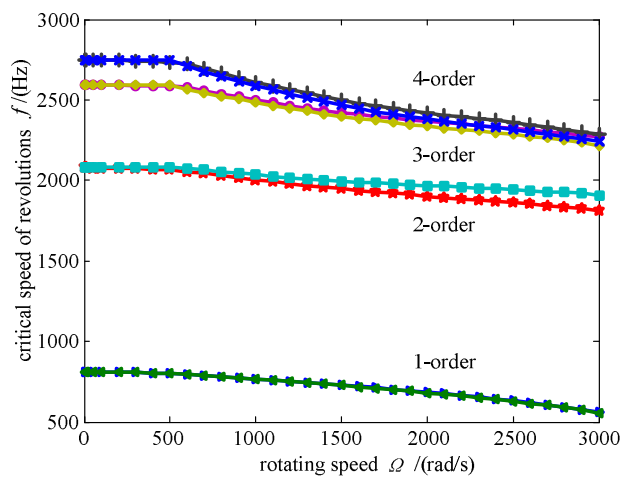

Fig. 6. Natural frequency of the spindle coupling system

As can be drawn from Table3, when the rotating speed is $3000 \mathrm{rad} / \mathrm{s}$, the coupling of various factors influence the natural frequencies larger than their individual role, next-order natural frequencies in coupling condition are $30.6 \%$ lower than in stationary state; the four-order natural frequencies are lower $16.9 \%$. which illustrates that the impact of various coupling factors is not linear superposition relationship, but non-linear coupling.

Table 3 The impact of coupling on high-speed spindle system dynamics characteristics / Hz

\begin{tabular}{cccccccc}
\hline \multirow{2}{*}{$\begin{array}{c}\text { exponent } \\
\text { number }\end{array}$} & Static & $\begin{array}{c}\text { Centrifugal } \\
\text { force }\end{array}$ & $\begin{array}{c}\text { Positive } \\
\text { precession }\end{array}$ & $\begin{array}{c}\text { Negative } \\
\text { precession }\end{array}$ & $\begin{array}{c}\text { Bearing } \\
\text { stiffness }\end{array}$ & $\begin{array}{c}\text { Negative } \\
\text { precession }\end{array}$ & $\begin{array}{c}\text { Positive } \\
\text { precession }\end{array}$ \\
\hline 1-order & 809.2 & 654.2 & 807.1 & 811.4 & 734.5 & 557 & 561.2 \\
2-order & 2079 & 2029 & 2031 & 2127 & 1915 & 1812 & 1910 \\
3-order & 2594 & 2552 & 2569 & 2619 & 2292 & 2217 & 2269 \\
4-order & 2747 & 2709 & 2709 & 2786 & 2310 & 2242 & 2284 \\
\hline
\end{tabular}

\section{Discussion and conclusions}

In this paper, through the finite element method combined with elasticity theory, the finite element model of spindle - bearing rotor system taking the role of speed into consideration is established. The impact of rotating speed on the dynamics characteristics of high speed spindle system is also analyzed, the main conclusions include:

(1) When the speed of the spindle system is lower than $500 \mathrm{rad} / \mathrm{s}$, the centrifugal force can be ignored; With the speed increasing, the impact of centrifugal force on 1-order natural frequency increases, while the impact on higher-order natural frequency is weak.

(2) As rotating speed increases, the impact of gyroscopic torque on the spindle dynamics gradually increases, mainly reflecting in the higher modes, the impact on the 1-order is less. 
(3) Through coupling the centrifugal force, gyroscopic moment and bearing stiffness, it is found that the impact of coupling factors on the dynamic characteristics of spindle system is greater than their individual effect, and various factors is not the linear superposition but nonlinear coupling. Therefore, due to the the rising of rotating speed, the centrifugal force, gyroscopic moment, bearing stiffness and the variation under the coupling effect which are induced by speed become the key factors influencing the dynamics characteristics ofmotorized spindle system.

\section{References}

[1] Liu Bin, Peng Manhua. The Present State and D evelopm ent in High Speed Cutting Technology[J]. MOULD \& DIEPROJEC, 2010, 10: 60-66.

[2] W. X. Tang, X. Ai, S. Zhang and H. Jiang. Dynamic Modeling for High-Speed Milling System with Centrifugal Force and Gyroscopic Effect[J]. Key Engineering Materials, 2004, 259-260: 848-852.

[3] Matti Rantatalo, Jan-Olov Aidanpaa, Bo Goransson, Peter Norman. Milling machine spindle analysis using FEM and non-contact spindle excitation and response measurement[J]. International Journal of Machine Tools \& Manufacture, 2007, 47: 1034-1045.

[4] Yuzhong Cao, Y. Altintas. Modeling of spindle-bearing and machine tool systems for virtual simulation of milling operations[J]. International Journal of Machine Tools \& Manufacture, 2007(47): 1342-1350.

[5] Chi-Wei Lin, Jay F. Tu. Model-Based Design of Motorized Spindle Systems to Improve Dynamic Performance at High Speeds[J]. Journal of Manufacturing Processes, 2007, 9(2): 94-108.

[6] Y. Altintas, E. Budak. Analytical Prediction of Stability Lobes in Milling[J]. Annals of the CIRP 1995, 4(1): 357-362

[7] Bert R. Jorgensen, Yung C. Shin. Dynamics of Spindle-Bearing Systems at High Speeds Including Cutting Load Effects[J]. Journal of Manufacturing Science and Engineering, 1998, 120: 387-394.

[8] Keivan Ahmadi, Hamid Ahmadian. Modelling machine tool dynamics using a distributed parameter tool-holder joint interface[J]. International Journal of Machine Tools \& Manufacture, 2007, 47: 1916-1928.

[9] E. Budak, A. Ertürk, H.N. Özgüven. A Modeling Approach for Analysis and Improvement of Spindle-Holder-Tool Assembly Dynamics[J]. CIRP Annals-Manufacturing Technology, 2006, 55(1): 369-372.

[10]Hongqi Li, Yung C. Shin. Analysis of bearing configuration effects on high speed spindles using an integrated dynamic thermo-mechanical spindle model[J]. International Journal of Machine Tools \& Manufacture, 2004, 44: 347-364.

[11]W. R. Wang, C. N. Chang. Dynamic Analysis and Design of a Machine Tool Spindle-Bearing System[J]. Journal of Vibration and Acoustics, 1994, 116: 280-285.

[12]Aini. R., Rahnejat. H. and Gohar. R. Experimental Investigation Into Bearing Induced Spindle Vibration[J]. Int. J. Mach. Tools Manuf., 1990, 30: 1-18.

[13]H. D. Nelson, J. M. McVaugh. The Dynamics of Rotor-Bearing Systems Using Finite Elements[J]. Journal of Engineering for Industry, 1976: 593-600.

[14]G.L. Xiong, J.M. Yi, C. Zeng, H.K. Guo, L.X. Li. Study of the gyroscopic effect of the spindle on the stability characteristics of the milling system[J]. Journal of Materials Processing Technology, 2003, 138: 379-384. 